\title{
Strong AI to Super-intelligence: How is AI placed vis-à-vis Intellectual Property Rights
}

\author{
Raju Narayana Swamy a, \\ ${ }^{a}$ Principal Secretary, Government of Kerala, India. \\ * Corresponding Author: narayan5@ias.nic.in
}

Received: 30-07-2021, Revised: 28-09-2021, Accepted: 01-10-2021, Published: 30-10--2021

\begin{abstract}
The paper analyses how Artificial Intelligence (AI) enabled systems can be brought into the Intellectual Property (IP) ecosystem. It dwells upon the question of AI- IP interface from three perspectives, viz., (a) AI as a technology to manage IPRs, (b) IP rights as an obstacle to the transparency of AI and, (c) patents as well as copyrights as legal systems that can foster AI. The three-step test for obtaining a patent- novelty, inventive step and utility - is looked at through the lens of AI technology. Issues such as patent evergreening, best vs worst embodiment and liability for illegal acts which cannot be traced to human actors are delved into. The article concludes with the need for a uniform treatment of the AI system across the board by bringing in an amendment to TRIPS and the necessity to usher in regulators for adjudication.
\end{abstract}

Keywords: Artificial Intelligence, Intellectual Property, Super-intelligence, Machine Learning, AI in India, IPR in India.

\section{Introduction}

Artificial Intelligence (AI) is the science and engineering of making shrewd machines. The term was officially instituted by [1] who alongside Marvin Lee Minsky coordinated the Dartmouth gathering in 1956. As per his vision, it is the thought of a program, preparing and following up on data to such an extent that the outcome corresponds to the way in which a smart individual would react in response to a comparable input [2] .In other words, AI is the capacity of a machine to impersonate a canny conduct. Such conduct, it should be referenced here, may arise either from a psychological methodology or a computational methodology.

In the Indian setting, the NITI Aayog conversation paper characterizes AI as "a star grouping of advances that empower machines to act with more significant levels of insight and imitate the human capacities of sense, appreciation and activity" (Sony. P \& Singh, V. Karthikey, 2019). This arrangement is to be seen in the context of the educational meaning of AI,as proposed by the research and advisory organization, Gartner Inc., as the technology that turn up to mimic and match human performance typically by acquiring and collating skills, making 
decisive conclusions, comprehendingmultifarioussubject matters, engaging in communication with the physical environment, strengthening human intellectual and perceptive actionsor superseding human involvement in execution of unusual tasks and missions (as cited in Sony\& Singh, 2019).

\section{From Weak AI to Strong AI and Super-intelligence}

The contemporary state of AI is prominently alluded to as frail AI. Its qualities are twofold, viz., (a) it has direct human intercession in its creation and, (b) it is restricted to a solitary errand. Siri, for instance, is a frail AI framework utilized by numerous individuals to help them even in daily routine tasks. The following phase of advancement is solid AI wherein human like deduction - with an emotional and cognizant psyche - is prompted. An exemplary model is a "Creativity Machine", commissioned by the US military to plan weapons (Sayler, M. Kelly, 2020). Some information technology researchers are of the assessment that solid AI frameworks may develop to geniuses, outperforming people in the manner of thinking.

\section{The Turing Test}

The Turing Test was proposed by Sir Alan Turing (1950), to ascertain if the outcomes being delivered by a machine are the result of its own insight or that of calculations and orders. The test called upon persons to interact with a machine or human and afterwards to conclude whether they could differentiate if they spoke to a human or a machine. Turing was of the view that an AI machine showed insight if the reactions submitted were indistinguishable from genuine human reactions. Regardless of the underlying achievement, the test endured turnaround in later years and its application was to a great extent confined to discourse machines and certain testing purposes.

\section{WIPO Classification}

The World Intellectual Property Organization (WIPO)propounded three classifications of AI, namely, master frameworks, insight frameworks and common language frameworks. Master frameworks are programs that tackle issues in particular fields of information like diagnosing ailments and suggesting treatment. They depend fundamentally on a hand-made information base and set of rules made by people. However, a framework that is wholly dependent on flow of information cannot scale and after a certain stage, master frameworks got rigid. Also, there are numerous genuine difficulties which are too unpretentious to be in any way addressed by shortsighted intelligent thinking that observes a bunch of rules composed by human specialists. Insight frameworks enable us to see the world with the feeling of sight and hearing. Acommon language program by contrast is planned to comprehend significance of words mulling over various syntactic and literary settings to give a semantic examination. (Kurzweil. R, 1990). 


\section{AI vs Machine Learning}

Latest advances in AI enable programming of PCs to gain from past experience. An exemplary model is identification of apples from among natural products in a bin of food supplies. By depicting what an apple resembles, we can program a PC so the machine can perceive apples dependent on their shape and shading. AI can be utilized to anticipate whether a client will default on a bank credit or to utilize side effects to foster a clinical determination. Independent driving is another feasible development forecasted with AI. Despite the fact that the numerical thoughts behind AI date back to many years, ongoing advances in information stockpiling, computational speed and sensors have drastically diminished the expense of AIbased forecasts. Obviously, AI is starting to make its presence felt increasingly, more in the everyday setting. An exemplary case is x.ai, a New York City - based startup, that gives a virtual individual associate to book arrangements over email and oversee schedules. A brief framework for understanding $\mathrm{AI}$ is illustrated in figure.1

\begin{tabular}{|l|l|}
\hline \multicolumn{1}{|c|}{ Human Intelligence } \\
$\begin{array}{l}\text { Cognitive Science (Thinking } \\
\text { Humanly) }\end{array}$ & $\begin{array}{l}\text { Natural Language Processing, Knowledge } \\
\text { Representation, Automated Reasoning } \\
\text { (Acting Humanly) }\end{array}$ \\
\hline Syllogism, Logic (Thinkin Rationally) & Rational Agent Models (Acting Rationally) \\
\hline
\end{tabular}

Figure 1. Framework for understanding artificial intelligence (Source: Russel and Novig, 2009 as cited in Kathuria et.al, 2020) [3]

Machine Learning is a subset of AI. The concept discusses the ability of machines to solve problems by learning through the data, beyond the programming and it involves three characters, namely, supervised learning, unsupervised learning and reinforced learning. Figure.2 illustrates the characteristics of AI and ML.

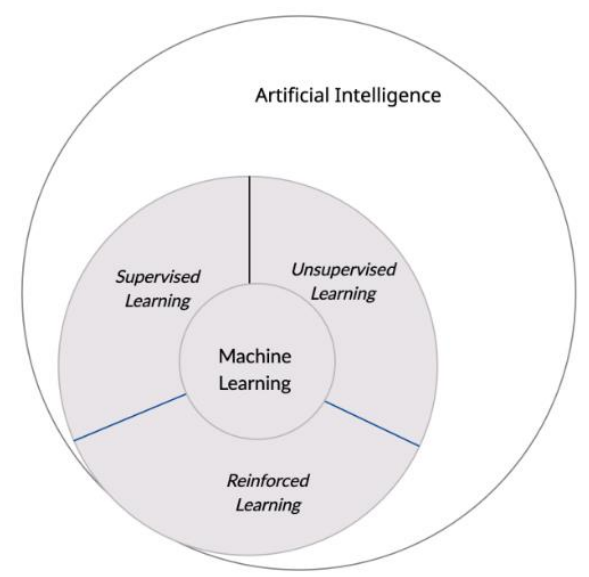

Figure 2. Machine Learning as a subset of AI. 
It is pertinent here to highlight the following concepts of deep realizing, reinforced learning and transfer discovering. Deep realizing mirrors the action in the layers of neurons in the cerebrum to figure out how to perceive complex examples in information. This maybe the most encouraging innovation where neural organizations are prepared on very huge informational collections. Reinforcement learningrelates to the programming specialists that learn objectiveoriented conduct by experimentation in a climate that gives prizes or punishments by accomplishing that objective. And the transfer discoveringrefers to that centers around utilizing information acquired in one issue to an alternate or related issue.

\section{The AI-IPR Intersection}

The AI-IPR convergence can be comprehensively arranged under three heads:

\section{i.AI as an innovation to oversee IPRs}

Across the globe, IP workplaces have conveyed different AI applications, exemplary models being WIPO Translate and WIPO Brand Image Search that utilize such applications for computerized interpretation and picture recognition. Notice should be made here of the 2018 gathering coordinated by WIPO to examine these applications and energize their sharing.

\section{ï.IP rights as an impediment to the straightforwardness of $A I$ frameworks}

In a period of straightforwardness and responsibility, an inquiry emerges regarding whether this necessity will keep on being fulfilled in cases wherein the AI cycle includes components that are misty for legitimate or mechanical reasons (Wexler, R., 2018).Indeed IP rights as a rule and proprietary innovations specifically could make hindrances and raise a contention between IP arrangements from one viewpoint and the social need of straightforwardness. The need of the hour lies in featuring the truth that revelation for fulfilling these objectives does not concern the algorithmic guidelines, but just their outcomes.

\section{iï.IP as a legal system that can protect, nay foster $A I$.}

Patent and copyright are the most pertinent frameworks of assurance with respect to AI. In any case, when patent laws were imagined, the idea of machine as a creator didn't exist. Along these lines patent laws overall presented innovation rights just to people.An example for this is the Japanese law specification implying that only an individual can be a creator, and not any machines. What's more, the circumstance has not gone through a sea change even today.To refer to a model, an AI framework dedicated as DABUS was named as the creator in patent applications documented in UK, US and Europe in 2017 [4].But the equivalent was dismissed in all the three because of it not being a legitimate individual.In this manner, from a patent point of view, the accompanying issues need extraordinary notice:

a. Whether AI as a development is qualified topic. (In many countries, calculations without help from anyone else qualify as dubious frameworks lacking specialized character and consequently cannot be ensured protection under IP laws. Nonetheless, 
it will be counterproductive in the event that we adopt a sweeping strategy that patents ought not be granted to AI-based creations )

b. Who is the valid and first innovator? (Should the law allow that the AI application be named as the creator or would it be advisable for it to be indicated that a person be named as the designer? Provided that this is true, should the law let the partners take the choice by interior courses of action with regards to how the human designer is to be resolved. In the event that we award patent to AI as designer, would it be able to be relegated to the gathering who will get most extreme benefit through commercialization? Would ownership be able to be chosen based on Coase Theorem?)

c. Who claims and is in this way obligated for the demonstrations of the AI innovation? Does the legitimate duty of the illicit activity of an AI lie with its proprietor or its client or its administrator? Should the position of the maker being at risk regardless of him lackingmensrea or even actus reus go through a radical change? In the event that the reason for the illicit demonstration cannot be attributed to a human entertainer, who has the risk?

d. Interpretation of non-obviousness

e. Issues relating to divulgence (explicitly how it very well may be satisfied where calculations of AI are not static but rather change over the long haul and handling best versus most exceedingly awful encapsulation issues: $\mathrm{AI}$ application maykeep the best exemplification undisclosed and get patent without total honesty.)

f. The manner in which any harms be resolved in case the AI copies a creation or replicates an innovation.

g. Adequateness of current laws. Should a sui generis arrangement of IP rights for AI produced creations be raised? Or on the other hand should the AI-IPR interface be required to be postponed till the D-day shows up when AI innovation is better perceived? (considering the way that at the current phase of improvement, instances created by totally self-sufficient AI frameworks are rare).

\section{The Indian Context: Patent Protection for AIs}

\section{Subject matter eligibility}

Artificial Intelligence empowered frameworks can make innovations which commonly result from the use of human intellectual cycles. Nonetheless, there are legal hitches. For example, the disallowance in Section 3(k) of the Indian Patents Act 1970 [5] (as altered in 2002)has triggered a hornet's nest and has led to patents at times being allowed to mixes of equipment and programming or programming with certifiable specialized applications. The Indian Patent Office's position on patentability of PC related developments needs clearness. Anyway a silver line is the elimination of the inflexible prerequisite of just programs related to a novel equipment being qualified for a patent. However, we have a long way to go. The need of great importance is a strong system for protecting AI developments, the sign of which will be 
consistency, consistently guaranteeing that the country stays responsive towards trend-setters. Dismissing all AI patents on the reason that all AI will utilize the fundamental modalities of information assortment, normalization, re-repeat/self-AI, information association, information handling and output as wanted by human cerebrum will be counterproductive. One can rely on the experience of the European Patent Office which has effectively held its first gathering on AI and patenting. Obviously, the focus of such a system will be to make India a maker of AI instead of a uninvolved adopter of the equivalent. Simultaneously, AI which can be a potential danger to mankind maybe sorted out as "destructible/perilous development".

Who can apply for a patent?

As innovation pushes ahead from a period of frail AI to solid AI, also of superintelligence, the query that evolves is whether AI innovations can be considered as creators. Be that as it may, this is as yet an ill-defined situation. Section 6 of the Patents Act, 1970 endorses that any individual professing to be the valid and first designer of the creation can apply for a patent. This expression is characterized in Section 2(1)(y) as follows:. It does exclude either the initial shipper of an innovation into India or an individual to whom a creation is first imparted outside India.

The part advances an exclusionary definition and doesn't explicitly express that the valid and first innovator ought to be a human. Thus the Act gives the fortitude to incorporation of works by AI frameworks. In any case, the drawing on the divider isn't so clear. For example, Section 2(1) (p) characterizes the expression "patentee" as an individual for the time being entered on the register as the grantee or owner of the patent (Indian Patent Act, 1970) [5]. The Act also talks about individuals occupied with or advancing exploration in the very field as that to which the creation relates.

The above discussion expresses the view that it ought to be an individual ( legal individual) and hence the aim of the governing framework for the Act overall can be perceived to be shifted towards entities which are persons in the eyes of law. This underlines the need to correct the enactment to suit the evolving scenario of advancing logical frameworks.

\section{The Three Step Test}

As regards innovations by AI empowered frameworks, the greatest test towards acquiring a patent is fulfilling the three stage test. The term 'new' is not characterized in the Act. In spite of the fact that the expression "new invention " is characterized in the Act, this definition is superfluous as the term is not utilized elsewhere in the Act. Consequently depending on the precedent-based law significance of the term, we can securely infer that a case is viewed as new if every one of the components of the case cannot be found in a solitary prior art, whichhere implies everything made accessible to general society through a composed or oral depiction, by use or in some other way before the date of development of the invention (Glaverbel SA vs. 
Dave Rose and Others, 2010 (43) PTC 630) [6] . The essential query that emerges with regard to $\mathrm{AI}$ can thus be expressed in the accompanying terms.

Tripathi and Ghatak (2018) [7], posed a question, "While an AI framework will unquestionably draw upon earlier craftsmanship, because of its administering human researchers taking care of input data, is it genuinely competent to arrive at a judgment on whether its innovation can represent something novel?"

The aspect of inventive step is more confounded. The Act defines the term under Section 2(ja).

The Supreme Court in the Novartis case separated Section 2(ja) into its components in the following way:

"It [The product] should appear because of a development which has an element that: (a) entails specialized development over existing information, or (b) has a monetary importance and furthermore, (c) makes the creation not clear to an individual gifted in the craftsmanship".

In the light of the abovementioned facts, it should be stated with regard to AIs that odds of making developments on existing models or ideas which are not clear to individuals talented in the workmanship is surely more hard to accomplish than mere novelty. Obviously, the innovation should initially progress to furnish these frameworks with a human-like insight so that careful decisions in the new circumstances can be made by them [7]

Issues identified with evergreening:

A significant inquiry that should be looked into is whether an AI patent application referring to another AI application will make the very nature of the creation crumble as even a minor intelligent change would prompt another development. Whether in such cases we need to bring in legal provisions akin to Section 3(d) of the Patent Act is an issue that should be debated exhaustively. Obviously, this point is significant not just to keep away from patent evergreening but in addition to manage the issue of patent trolls.

\section{Issues relating to provisional applications:}

The approaches towards the manner in which thetemporary applications need to be permitted (as simple expression of thought to guarantee priority date will give a timeline of one year to widen claims to a limitless degree) should be examined.

\section{Copyright and AI}

The primary inquiry brought up in this setting is whether copyright ought to be credited to unique scholarly and imaginative works that are in self-governing mode, produced by AI or should a human maker be required. It should be referenced here that even craftsmanship of Picasso have been reproduced by AIbased frameworks and in 2018, one such work was sold for close to half a million US dollars [8]. In any case, the reality stays that AI workmanship is a subset 
of generative craftsmanship and is algorithmic - repeatable in nature to be explicit - and regularly open source - shareability being its trademark. One side contends that systems cannot be as inventive as humans while the other argue it contrary (Gelender, 1994). The most acknowledged answer as on date is that, while AI applications are fit for delivering such works in self-governing mode, this limit does not fit with the copyright framework which is after all connected with the human inventive soul. The practitioners consider the Lovelace test to be better than the Turing test. Hypothetically, Lovelace states the viewpoint that machines do not possess inventiveness [9], highlighting the rationale that inventiveness is the capacity to do the eccentric, dissimilar to something machines consistently do. Machines, the corridor sign of which, is rule bound to conduct (and hence AIs) cannot be brought within the ambit of copyright framework. The counter view depends on decisions that the nonhuman idea of the wellspring of a work ought not be a bar to copyright.

The US copyright office's update to the Compendium of Practices (December, 2014) adds weight to the first view.Nonetheless, theIPClause of the US Constitution does not unequivocally specify a human necessity. Notice additionally should be made of the WIPO meaning of IP that dwells on manifestations of the psyche yet does not determine whether it should be a human imaginative mind.Notwithstanding these, as of late a San Francisco Court held that creatures not being people do not have locus standi under Copyright Act to sue for infringement [10]. Obviously, the judgment built up contentions that if Naruto, the monkey cannot sue for copyrightviolation, comparable ought to be the circumstanceforAIframeworks. Also, as appropriately brought up by [7] regardless of whether nations confessed to giving copyrights to works crafted by an AI, the topic of who gets that copyright stays mysterious in the light of the fact that the current status of law requires a legitimate personhood of a holder, something which an AI needs except if its maker is conceded that for its sake. Nonetheless, what occurs if the AI framework was based on sale-purchase remains an open question. The appropriate response lies for the maker in nations like England and New Zealand, however this actually does not address the above question in its totality.

Three milestone decisions need references here:

\section{a.Burrow Gilles Lithographic Co. v Sarony (III US 53 (1884)) [11]}

The case talked about the chance of giving copyright assurance to an item which is the yield of a machine. The Court held that absolutely mechanical work is essentially not imaginative. If methodology on these lines is followed, allowing copyright for works made by AI would be troublesome.

b. Bleistein v Donaldson Lithographing Co, 188 US 239 (1903) [12]

Justice Holmes depicted the uniqueness of human character and specified it to be essential to get a copyright.

c. Alfred Bell and Co v Catalda Fine Arts Inc. 191 F. 2d 99 (2d Cir, 1951) [13] 
The Court brought down the norm for originality and held that for the work to be so , it should not be a duplicated one. This judgment was a relief for the promoters of copyrights for AI created works as it is not replicated despite the fact that it is produced through calculations.

In the Indian setting, the test to copyright for works of AI is Section 2(d) of the Copyright Act, 1957 which defines author as a person.

For an individual to make a work, nearness of the individual with the work is significant and thus person here implies a human or a legal individual, a lot to the dismay of promoters of copyright to AI frameworks.

\section{Conclusion}

As we move away from IA (Intelligent Automation) to AI driven by machines, the inquiries around ramifications of such an innovation are developing. Daimler-Benz has effectively tried self-driving trucks on open streets, AI innovation has been applied successfully in clinical headways, a film composed by an AI appeared online as of late and AI has even discovered its way into the advocate fraternity. Also, Sophia, a social humanoid robot created by Hanson Robotics, a Hong Kong based organization as of late turned into a citizen. Another energizing field interweaved with AI is the idea of Artificial Neural Networks (ANNs) frameworks of equipment and programming designed after the activity of neurons in the, cerebrum. Neural nets are viewed as venturing stones in the quest for AI. The principal computational model of ANNs - prevalently called threshold logic - was created by Warren Mc Culloch and Walter Pitts in 1943 (Palm, G., 1986) [14]. .From there on ANNs have progressed significantly especially due to their particular capacity to distinguish the fundamental connection between various arrangements of information and because of their dynamic nature - adjusting to changes in yield so that they give the best achievable outcome without changing the input nodes. A significant capability of ANNs lies in the fiscal field. Anyway exactness of ANNs relies upon the design chosen for a particular issue and training pattern of ANNs, among different elements.

Add to this, the issue of "deep fakes" and the situation is much more intricate. These are AI-improved phony pictures and recordings that take influence of an AI calculation to embed faces and voices into video and sound chronicles of real individuals and empowers the making of impersonations wrongly depicting individuals saying or doing things they never said or did. In 2012, an AI chatbot named Sim Simi purportedly figured out how to show itself 'Thai' through correspondence with clients in Thailand. Utilizing the new dialect and expressions, it had gained from dealings with clients, Sim Simi went on purportedly to slander the Thai Prime Minister (Metaratings, 2012) [15]

In this unfurling situation, what is required is a uniform treatment of the AI framework in all cases wherein countries who are signatories to multilateraltrading arrangements start to perceive its presence by getting through a revision to TRIPS. Passing of an AI Information Insurance Act which could introduce the institution of a controller to settle and adjudicate acts 
of AIs and all the more explicitly set forth solutions for common and criminal offences carried out by them is additionally the need of great importance. It should bring in laws to keep honest makers from being indicted for demonstrations of the AI for which they have no control what so ever. Also, these actions should introduce visionary advances focused at determining how solid $\mathrm{AI}$ and superintelligence ought to be treated in the IP system. For, we must be ready for the Dday when machines implement, safeguard and even indict. Obviously, the test before the comity of countries and its inhabitants is to bridle this stunning innovation for the advancement of humankind by establishing the framework of a strong legitimate system, nay an AI explicit, yet humankind driven law.

\section{References}

[1] Mccarthy, J., Minsky, M., Rochester, N. \& Shannon, C.E. (2006). A Proposal for the Dartmouth Summer Research Project on Artificial Intelligence, AI Magazine, 27, 1-3.

[2] Raquel Acosta, R., (2012), Artificial Intelligence and Authorship Rights, HarvardJournal of Law and Technology, 17

[3] Kathuria, R., Kedia, M., \& Kapilavai, S. (2020). Implications of AI on the Indian Economy, Indian Council for Research on International Economic Relations, New Delhi.

[4] Ireland, Imogen., \& Lohr, Jason. (2020), DABUS': the AI topic that patent lawyers should be monitoring, ManagingIP.

[5] Indian Patent Act (1970), available at https://ipindia.gov.in/writereaddata/Portal/IPOAct/1 31 1 patent-act-197011 march2015.pdf.

[6] Glaverbel SA vs Dave Rose and Others, 2010 (43) PTC 630, https://vlex.in/vid/ glaverbel-s-vs-dave-572132818.

[7] Tripathi, S., Ghatak, C., (2018), Artificial Intelligence and Intellectual Property Law, Christ University Law Journal, 7, 83-97. https://doi.org/10.12728/culj.12.5

[8] Emerging Technology from the arXi, (2019), MIT Technology Review, https://www.technologyreview.com/2019/09/20/132929/this-picasso-painting-had-neverbeen-seen-before-until-a-neural-network-painted-it/

[9] Neill, Sean. O., (2014). How Creative Is Your Computer?, New Scientist.

[10] Naruto Vs. Slater., (2018). United States Court of Appealsfor The Ninth Circuit, Jusita Us Law,

[11] Burrow-Giles Lithographic Company v. Sarony, (1884). (III US 53 (1884) https://supreme.justia.com/cases/federal/us/111/53/ 
[12] Bleistein vs Donaldson Lithographing Company, (1903). 188 US 239 https://supreme.justia.com/cases/federal/us/188/239/

[13] Alfred Bell \& Co. Ltd. v. (1951). Catalda Fine Arts Inc., 191 F. 2d 99 (2d Cir, 1951) https://law.justia.com/cases/federal/appellate-courts/F2/191/99/91570/

[14] Palm G., (1986). Warren McCulloch and Walter Pitts: A Logical Calculus of the Ideas Immanent in Nervous Activity, Brain Theory, Springer, Berlin. https://doi.org/10.1007/978-3-642-70911-1_14

[15] Metaratings., (2017), SimSimi chatbot banned in Thailand, Telecom Asia, https://www.telecomasia.net/blog/content/simsimi-chatbot-banned-thailand/

\section{Funding:}

No funding was received for conducting this study.

Conflict of interest:

The Author has no conflicts of interest to declare that they are relevant to the content of this article.

\section{About The License:}

(C) The Author 2021. The text of this article is open access and licensed under a Creative Commons Attribution 4.0 International License 